\title{
AVALIAÇÃO DA COMPOSTAGEM DE CARCAÇAS DE FRANGO PELOS MÉTODOS DA COMPOSTEIRA E DE LEIRAS ESTÁTICAS AERADAS
}

\author{
ED CARLO R. PAIVA ${ }^{1}$, ANTONIO T. DE MATOS ${ }^{2}$, MÔNICA A. AZEVEDO ${ }^{3}$, \\ RENATA T. P. DE BARROS ${ }^{4}$, TATIANA D. R. COSTA ${ }^{5}$
}

\begin{abstract}
RESUMO: Avaliaram-se a compostabilidade de diversos resíduos adequadamente misturados e a eficiência de diferentes processos (leiras estáticas aeradas e composteira) na eliminação de microrganismos e tempo de compostagem. Tratamentos: composteira: palha de café, cama de frango e carcaça de frango, LEA 01: bagaço de cana-de-açúcar, cama de frango e carcaça de frango inteira, LEA 02: bagaço de cana-de-açúcar, cama de frango e carcaça de frango triturada, LEA 03: palha de café, cama de frango e carcaça de frango triturada. Variáveis monitoradas: temperatura, relação $\mathrm{C} / \mathrm{N}$, sólidos voláteis (SV), pH e umidade, além de avaliar a eliminação de Salmonella e a redução de coliformes termotolerantes. Os resultados obtidos para redução de SV foram 20,87\% (composteira), 25,31\%; (LEA 01), 28,86\% (LEA 02) e 54,48\% (LEA 03).
\end{abstract}

PALAVRAS-CHAVE: carcaça de frango, compostagem, composteira, leiras estáticas aeradas.

\section{ASSESSMENT OF THE COMPOSTING OF POULTRY CARCASSES BY BIN METHODS AND AERATED STATIC PILES}

\begin{abstract}
It was evaluated the compostability of various waste properly mixed and the efficiency of different processes (aerated static piles and bin compost) in the elimination of microorganisms and time of composting. The experiments were built and monitored with the following compositions: bin method - coffee straw, poultry litter and poultry carcasses, ASP 01 sugar cane bagasse, poultry litter and poultry carcasses; ASP 02 - sugar cane bagasse, poultry litter and ground poultry carcasses; ASP 03 - coffee straw, poultry litter and ground poultry carcasses. The parameters monitored during the process, were: temperature, $\mathrm{C} / \mathrm{N}$ ratio, volatile solids (VS), $\mathrm{pH}$ and water content, besides Salmonella elimination and thermotolerants coliforms reduction were evaluated. The results obtained for the reduction of VS $20.87 \%$ (bin method), $25.31 \%$ (ASP 01), $28.86 \%$ (ASP 02) and 54.48\% (ASP 03).
\end{abstract}

KEYWORDS: poultry carcasses, composting, bin compost, aerated static piles.

\section{INTRODUÇÃO}

O Brasil é hoje um dos maiores produtores e o maior exportador de carne de frango do mundo. A criação de frango e a produção brasileira de carne de frango crescem a cada ano e, consequentemente, a quantidade de resíduos gerados na atividade. Segundo dados da União Brasileira de Avicultura e da Associação Brasileira de Exportadores de Frango, em 2009, o Brasil produziu aproximadamente 11 milhões de toneladas, o que representou cerca de $15 \%$ da produção total no mundo (UBA, 2010). Porém, ressalta-se que o índice de mortalidade informado pode ser considerado elevado quando comparado aos atuais que, segundo MIZUSAKI (2007), varia de 1 a $5 \%$. Vários trabalhos têm comprovado a eficiência da compostagem para o tratamento de carcaças de aves utilizando diferentes materiais estruturantes e fontes de carbono, dentre os quais podem ser citados COSTA et al. ( 2006), KUMAR et al. (2007), ORRICO JUNIOR et al. (2010) e ABREU et

\footnotetext{
${ }^{1}$ Prof. Adjunto, curso de Engenharia Civil, Universidade Federal de Goiás, Câmpus Catalão.

${ }^{2}$ Prof. Associado, Departamento de Engenharia Agrícola, Universidade Federal de Viçosa.

${ }^{3}$ Profa. Adjunta, Departamento de Engenharia Civil, Universidade Federal de Viçosa.

${ }^{4}$ Eng $^{\mathrm{a}}$ Agrícola e Ambiental pela Universidade Federal de Viçosa.

${ }^{5}$ Estudante de graduação em Engenharia Agrícola e Ambiental pela Universidade Federal de Viçosa.

Recebido pelo Conselho Editorial em: 4-2-2011

Aprovado pelo Conselho Editorial em: 19-5-2012
} 
al. (2011). Porém, em todos esses trabalhos, o material em compostagem tem sua primeira fase desenvolvida em composteira e, em geral, seguida de uma segunda fase por reviramento (Windrow).

O processo de compostagem por Leiras Estáticas Aeradas (LEAs) tem sido um dos mais difundidos para o tratamento de resíduos orgânicos, por apresentar custos de operação similares ao processo “Windrow”(STENTIFORD et al., 1996), além de grande eficiência na eliminação de patógenos contidos no material.

Devido a essas características, acredita-se que tal processo possa ser alternativa viável ao tratamento dos resíduos gerados na produção de frango no Brasil. Nesse sentido, no presente trabalho, tiveram-se como objetivos avaliar a eficiência do processo e a qualidade microbiológica do composto produzido em LEA e composteira, no tratamento da carcaça de frango, utilizando-se como materiais estruturantes e fontes de carbono, de bagaço de cana-de-açúcar, palha de café e cama de frango.

\section{MATERIAL E MÉTODOS}

O experimento foi conduzido em duas etapas, nas dependências do Departamento de Engenharia Agrícola (DEA) da Universidade Federal de Viçosa, no período de julho de 2007 a janeiro de 2008. Na primeira etapa, objetivou-se encontrar a proporção adequada $(10 \leq \mathrm{C} / \mathrm{N} \leq 20)$ dos resíduos a serem compostados por meio das leiras estáticas aeradas, mediante a determinação da relação carbono-nitrogênio $(\mathrm{C} / \mathrm{N})$ de cada material e da perda de pressão do ar, ao passar pela massa em compostagem, sendo, neste caso, adotada a mesma metodologia utilizada por MOREIRA et al. (2008) e SILVA et al. (2008). Os materiais utilizados na compostagem foram cama de frango, o bagaço de cana-de-açúcar, a palha de café e a carcaça de frango. A segunda etapa contemplou os experimentos de compostagem. As carcaças e camas de frango, bagaço de cana-de-açúcar e a palha de café foram obtidas em granjas e fazendas da região da Zona da Mata mineira.

Os processos de tratamento avaliados foram o método da composteira e o de compostagem em LEAs, com aeração forçada positiva. O primeiro processo consistiu em preencher a composteira e deixá-la em repouso (sem intervenção) por 60 dias e, depois disso, promover reviramentos periódicos, de acordo com as recomendações de PEREIRA NETO (2007), até sua completa estabilização. O segundo processo consistiu em montar leiras estáticas aeradas contendo, cada uma, um ventilador centrífugo (motor elétrico de $1 / 4 \mathrm{HP}$ de potência) de funcionamento controlado por timer analógico (precisão de 15 minutos) e termostato digital (precisão de $0,1{ }^{\circ} \mathrm{C}$ ). As leiras foram montadas com seção transversal trapezoidal (LEA 01) e triangular (LEA 02 e 03), com medidas aproximadas de $2 \mathrm{~m}$ de base maior, 1,5 $\mathrm{m}$ de base menor (LEA 01), 1 metro de altura e comprimento de $3 \mathrm{~m}$.

Na Figura 1, está apresentado o croqui esquemático do equipamento utilizado na primeira etapa deste trabalho, com o objetivo de determinar a perda de pressão do ar ao passar pelo material a ser compostado. O equipamento é constituído dos seguintes componentes: (1) coluna de chapa galvanizada, medindo 1,0 m de altura, com seção circular de 0,30 m de diâmetro; (2) tomadas para medição da pressão estática, representadas por sete tubos de cobre (5 $\mathrm{mm}$ de diâmetro) distanciados em 0,20 m no sentido vertical, em torno da coluna; (3) piso perfurado, constituído por chapa com furos circulares; (4) câmara plenum, em madeira, de seção quadrada $(0,55$ x 0,55 m), com 0,33 m de altura; (5) tubo de chapa galvanizada, medindo $1,20 \mathrm{~m}$ de comprimento por $0,10 \mathrm{~m}$ de diâmetro, responsável pela condução do ar insuflado pelo ventilador até o plenum; (6) homogeneizador, para uniformização do fluxo de ar (não usado no presente trabalho); (7) ventilador centrífugo de pás retas, acionado por motor elétrico, com potência de $1 / 4 \mathrm{HP}$; (8) diafragma fixo à entrada de ar, para possibilitar a variação na vazão. 


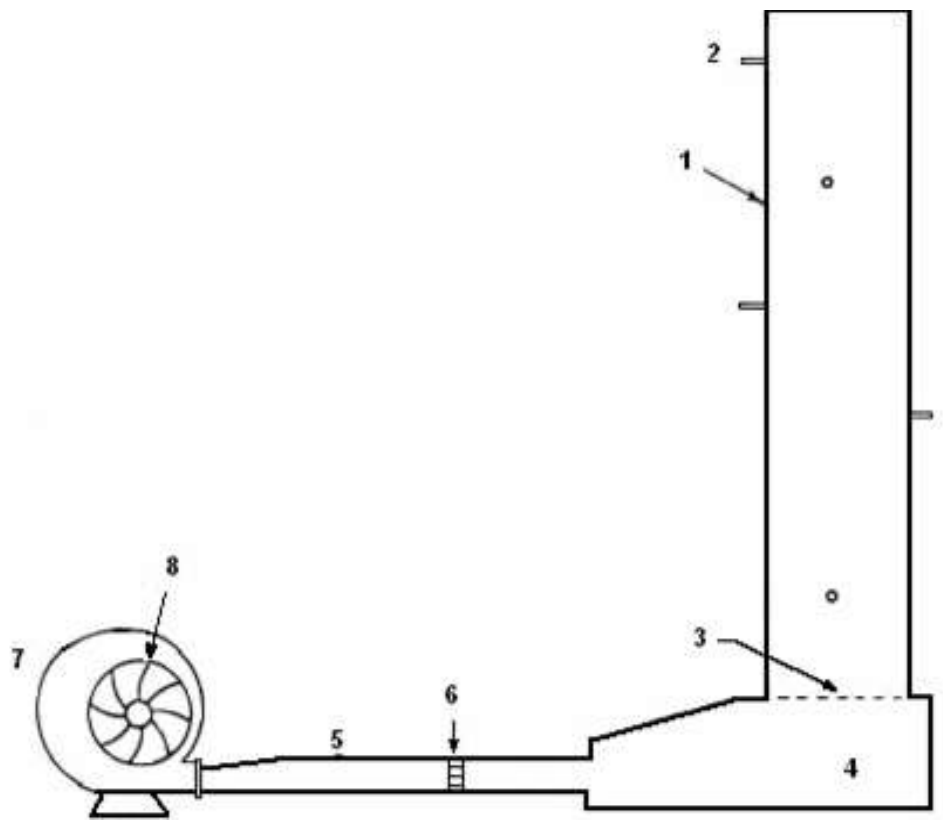

FIGURA 1. Esquema de protótipo utilizado na determinação do gradiente de pressão estática sob diferentes fluxos de ar (MOREIRA et al., 2008). Scheme prototype used in determining the gradient of static pressure under different air flows.

O enchimento da coluna de chapa galvanizada foi realizado colocando-se os materiais prémisturados, até a altura de $1 \mathrm{~m}$, sendo realizadas as medidas de pressão estática nas posições verticais de 0,2; 0,4; 0,6;0,8 e 1,0 m, utilizando-se de um manômetro digital. As medições de queda na pressão estática do ar forçado nas pilhas de material foram realizadas com duas repetições, para cada proporção de material, cama de frango e bagaço de cana-de-açúcar. As proporções, volume/volume, avaliadas foram: $20 \%$ de bagaço de cana-de-açúcar e $80 \%$ de cama de frango, $30 \%$ de bagaço de cana-de-açúcar e $70 \%$ de cama de frango e $40 \%$ de bagaço de cana-de-açúcar e $60 \%$ de cama de frango. As mesmas verificações foram feitas substituindo-se as proporções de bagaço de cana por palha de café. Neste trabalho, foi utilizada uma única vazão média de $4 \mathrm{~m}^{3} \mathrm{~min}^{-1}$ que correspondeu ao diafragma totalmente aberto.

Os experimentos foram montados e monitorados, apresentando inicialmente os seguintes valores médios para as variáveis relação $\mathrm{C} / \mathrm{N}$ e $\mathrm{SV}$, respectivamente. Tratamento 1: composteira $(19,2 ; 82,72)$ : carcaças de frango inteiras, palha de café e cama de frango. Tratamento 2: LEA 01(13,8; 86,04): carcaças de frango inteiras, bagaço de cana-de-açúcar e cama de frango. Tratamento 3: LEA 02 (13,8; 86,04): carcaças de frango trituradas, bagaço de cana-de-açúcar e cama de frango. Tratamento 4: LEA 03(13,6; 86,06): carcaças de frango trituradas, palha de café e cama de frango. As proporções dos materiais (cama de frango, bagaço de cana-de-açúcar, carcaça de frango e água) utilizados na montagem dos diferentes tratamentos seguiram as recomendações de DAM et al. (2009), tendo sido utilizados $0,3 \mathrm{~kg}$ de bagaço de cana-de-açúcar ou palha de café para cada $1 \mathrm{~kg}$ de carcaça de frango e $2 \mathrm{~kg}$ de cama de frango.

A composteira foi construída com uma área e altura útil de $(1,5 \times 1,5) \mathrm{m}^{2}$ e 1,5 m, respectivamente, e as LEAs com aproximadamente $2 \mathrm{~m}$ de base, $1 \mathrm{~m}$ de altura e $3 \mathrm{~m}$ de comprimento. A composteira e a LEA 01, montadas com carcaças de frango inteiras, foram montadas de forma estratificada, segundo recomendações de DAM et al. (2009). Para a composteira, a sequência de montagem foi primeiro colocar uma camada de $45 \mathrm{~cm}$ de cama de frango seca no fundo, depois uma camada de $15 \mathrm{~cm}$ de palha de café e então uma camada de carcaças, cobrindo em seguida com cama de frango até haver a formação de uma camada de, pelo menos, $5 \mathrm{~cm}$ de material sobre as carcaças. Adicionou-se água (o equivalente a $20 \%$ da massa das carcaças) sobre o material, para umedecê-lo. Repetiu-se essa sequência até ser colocada a última camada de aves. Cobriu-se, então, a pilha de material com uma camada dupla de cama de frango 
seca. Para LEA 01, obedeceu-se à mesma sequência, porém com a cama de frango e o bagaço de cana, misturados antes da colocação no fundo, entre as carcaças e a cobertura final.

$\mathrm{Na}$ montagem das LEAs 02 e 03, que utilizaram carcaças de frango trituradas, antes da montagem os resíduos foram pré-misturados, buscando sua homogeneização, sendo, em seguida, montadas segundo recomendações de PEREIRA NETO (2007).

As variáveis monitoradas foram: temperatura, em três pontos da massa (base, centro e topo), $\mathrm{pH}$, relação $\mathrm{C} / \mathrm{N}$, sólidos voláteis $(\mathrm{SV})$ e o conteúdo de água. As temperaturas foram monitoradas diariamente, a relação $\mathrm{C} / \mathrm{N}$ e SV (em base seca) foi determinada nas LEAs a cada 15 dias (nos primeiros 60 dias), na composteira a cada 20 dias (nos primeiros 60 dias) e, para todos os tratamentos, seguiu-se uma última determinação aos 90 dias. O conteúdo de água foi determinado pelo método da estufa (KIEHL, 1985), semanalmente nas leiras, com exceção da LEA 01, que passou a ser determinada a partir do $23^{\circ}$ dia, e na composteira, porém, nesta última somente após os primeiros 60 dias. As análises de SV, carbono orgânico facilmente oxidável (CFO) (DEFELIPO \& RIBEIRO, 1997) e nitrogênio total Kjedahl e conteúdo de água (STANDARD METHODS, 1998). As análises bacteriológicas de salmonella e coliformes termotolerantes foram realizadas segundo a instrução normativa IN 62, de 26 de agosto de 2003, Ministério da Agricultura Pecuária e Abastecimento.

Na condução dos experimentos em LEAs, buscou-se manter o conteúdo de água na faixa de 45 e 55 dag kg${ }^{-1}$, considerada ideal, segundo KIEHL (1985) e PEREIRA NETO (2007), para rápida degradação do material orgânico. Além da aplicação periódica de água, desenvolveu-se um dispositivo para as LEAs, tal como apresentado na Figura 2, composto por galão de plástico contendo água mantida até a altura de uma boia, obrigando o ar a passar através dele antes de chegar à leira.

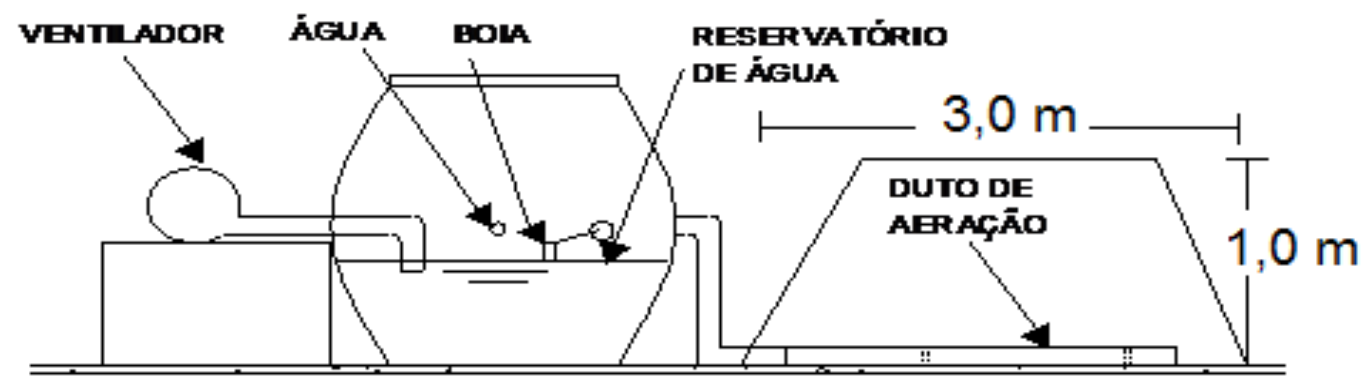

FIGURA 2. Esquema do sistema de umedecimento do material contido nas leiras. Scheme of the wetting system of the material contained in the piles.

Para consideração do fim da fase ativa, bem como da fase de maturação, foram seguidas as recomendações apresentadas por KIEHL (1985). Assim, o fim da fase ativa de degradação foi considerado alcançado quando a relação $\mathrm{C} / \mathrm{N}$ do material passou a ser menor que 18/1 e/ou a temperatura das pilhas menor que $40^{\circ} \mathrm{C}$. Findada a fase ativa, os materiais das leiras e da composteira foram transportados para pátio de estabilização de material orgânico do Laboratório de Engenharia Sanitária e Ambiental do Departamento de Engenharia Civil. Nesse local, foram efetuadas as correções no conteúdo de água todas as vezes que este se encontrava fora da faixa recomendada e citada anteriormente, sendo semanalmente revirado. A fase de maturação foi considerada findada quando a relação $\mathrm{C} / \mathrm{N}$ no material ficou em torno de 10/1, valor indicativo de estabilização do material, conforme sugerido por KIEHL (1985).

Os resultados da redução de Sólidos Voláteis (SV) foram submetidos ao tratamento estatístico, por meio de delineamento fatorial $4 \times 2$, com quatro diferentes tratamentos Composteira, LEA 01, LEA 02 e LEA 03, com três repetições em cada evento, e dois períodos de análise, aos 60 e 90 dias de processo. Utilizou-se, para a comparação de médias, o teste Tukey, a 5\% de probabilidade. 


\section{RESULTADOS E DISCUSSÃO}

$\mathrm{Na}$ Figura 3, estão apresentadas as variações de temperatura, em função do tempo de compostagem, nos tratamentos composteira (primeira e segunda fases), LEA 01, LEA 02 e LEA 03.

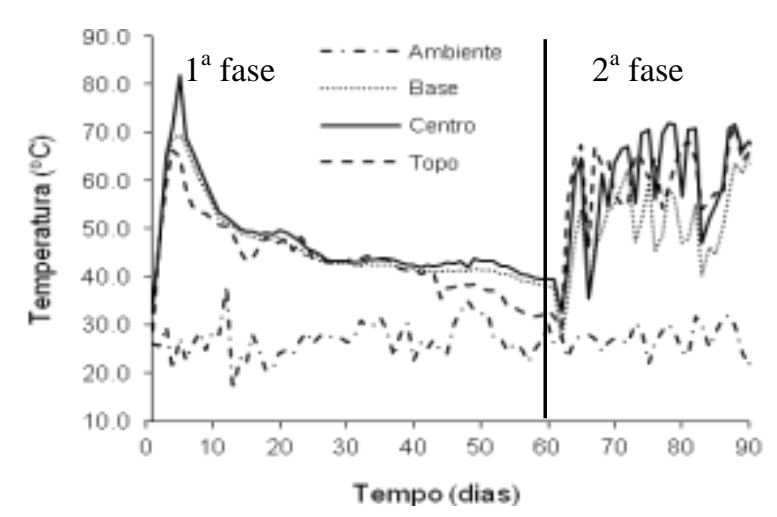

(a)

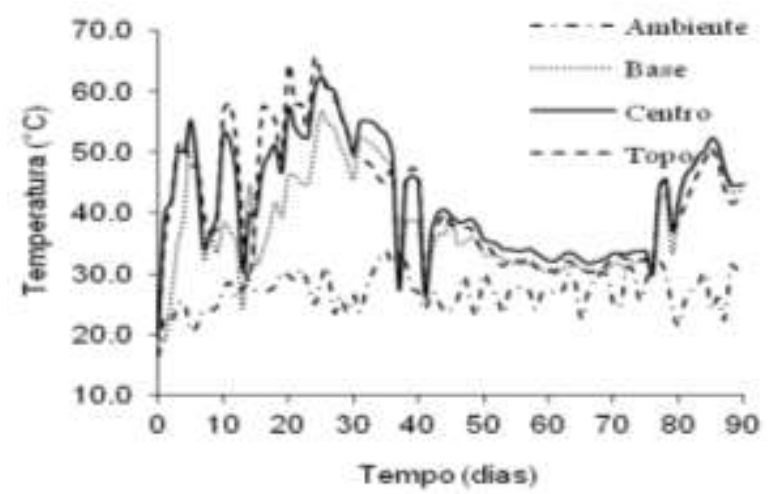

(c)

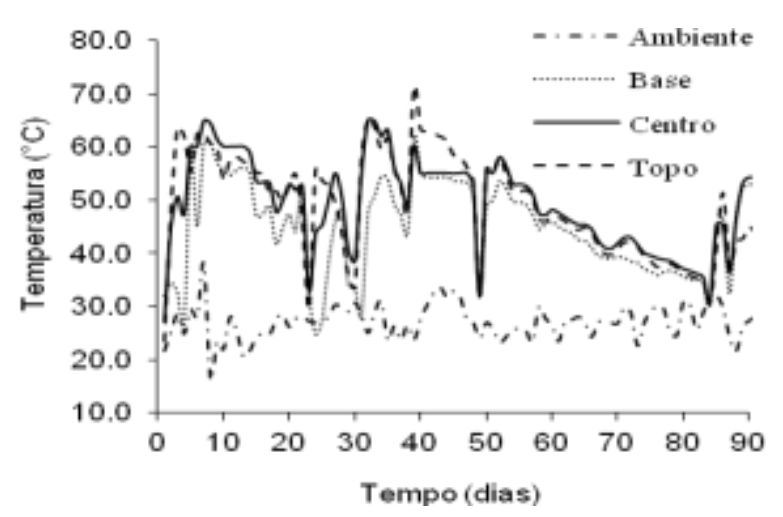

(b)

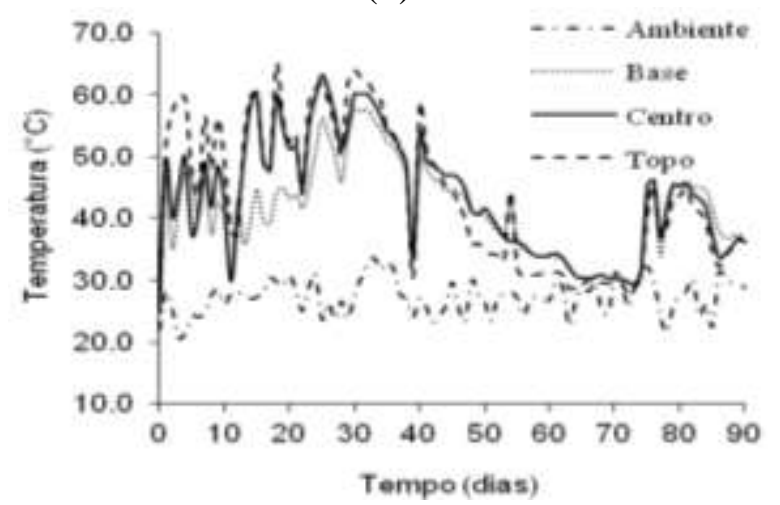

(d)

FIGURA 3. Variação da Temperatura em função do tempo de compostagem. (a) composteira; (b) LEA 01; (c) LEA 02 e (d) LEA 03. Variation of temperature versus time of composting. (a) Bin compost, (b) ASP 01, (c) ASP 02 and (d) ASP 03.

A variação da temperatura no material da composteira (Figura 3a), atingindo o pico de $82{ }^{\circ} \mathrm{C}$ no centro da pilha, no $4^{\mathrm{O}}$ dia, e decrescendo continuamente até o $60^{\circ}$ dia quando este foi retirado (fim do $1^{\circ}$ estágio), enquanto que, o novo aumento na temperatura do material observado no segundo estágio de compostagem indica que fatores ambientais (notadamente o conteúdo de água e a oxigenação) estariam condicionando o processo de degradação do material dentro da composteira. Segundo PUYUELO et al. (2010), a temperatura e o conteúdo de oxigênio podem ser considerados as principais variáveis utilizadas para avaliar a atividade microbiana . A remoção do material da composteira, a adição de água e o reviramento periódico permitiram que substratos de fácil degradabilidade fossem transformados com geração de energia, retomando-se, de certa forma, a fase termofílica. Se no primeiro estágio de degradação o período de altas temperaturas no material pode ser considerado curto, as altas temperaturas alcançadas pelo material no segundo estágio podem ter complementado o período necessário de altas temperaturas, indispensável para que se alcançasse a eliminação dos patógenos presentes no material. Na LEA 01 (Figura 3b), a temperatura do material subiu gradativamente, no início do processo, atingindo $60^{\circ} \mathrm{C}$ (centro) no sexto dia após a montagem da leira. Manteve-se próxima ou acima de $55^{\circ} \mathrm{C}$, em todos os pontos monitorados, por 8 dias, provavelmente enquanto as condições de umidade e aeração eram adequadas. A temperatura do material da LEA 02 (Figura 3c) aumentou gradativamente, atingindo $50^{\circ} \mathrm{C}$ (centro) no terceiro dia após a montagem. Acredita-se que taxa de aeração inadequada, associada à falta de um sistema eficiente de umedecimento, fez com o material apresentasse, em grande parte do tempo, temperaturas próximas a $40{ }^{\circ} \mathrm{C}$, valor insuficiente para se conseguir controle sanitário do composto. 
A temperatura do material da LEA 03 (Figura 3d) aumentou gradativamente, atingido $60{ }^{\circ} \mathrm{C}$ (topo), já no terceiro dia após a montagem da leira.

Em termos gerais, as LEAs 02 e 03 tiveram, nos primeiros 15 dias, comportamento muito semelhante, denotado por baixas temperaturas no material, ocorrendo alguns picos depois de efetuada a correção no conteúdo de água do material, como ocorreu a partir do $23^{\circ}$ dia de compostagem, quando foi instalado o sistema de umedecimento do material. Nessa ocasião, as temperaturas alcançaram valores dentro da faixa ideal para eliminação de patógenos, que está entre $55^{\circ} \mathrm{C}$ e $60^{\circ} \mathrm{C}$, mantendo-se nessa faixa por maior período de até 12 dias, enquanto antes da instalação do sistema de umedecimento, a temperatura manteve-se acima de $50^{\circ} \mathrm{C}$ por um período de três a cinco dias.

Observou-se, em todos os tratamentos, a elevação da temperatura sempre que o conteúdo de água do material era corrigido para, aproximadamente, $55 \mathrm{dag} \mathrm{kg}^{-1}$. Entretanto, a temperatura da base das leiras manteve-se sempre inferior às demais. Isto ocorreu devido a sua proximidade com o duto de aeração, locais em que a perda de água foi mais rápida que nos demais pontos da leira. Segundo WANG et al. (2011), o escoamento de ar unidirecional, tal como utilizado neste trabalho, pode causar diferenças espaciais no conteúdo de água no material, o que poderia causar prejuízos à dinâmica da degradação microbiana e ao progresso da compostagem no sistema estático. Os mesmos autores consideram que, mesmo em sistemas estáticos, é imprescindível o reviramento periódico para garantir um produto final uniforme e sanitizado. A aeração unidirecional por insuflação favoreceu um gradiente de temperatura no sentido ascendente, proporcionando a migração de umidade e sua condensação acerca de $10 \mathrm{~cm}$ da superfície das leiras.

$\mathrm{Na}$ Figura 4, está apresentada a variação da relação $\mathrm{C} / \mathrm{N}$ em função do tempo de compostagem para todos os tratamentos.

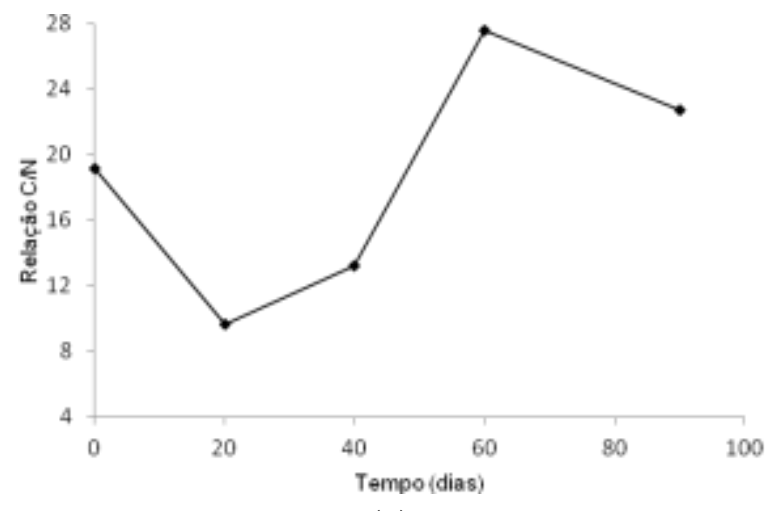

(a)

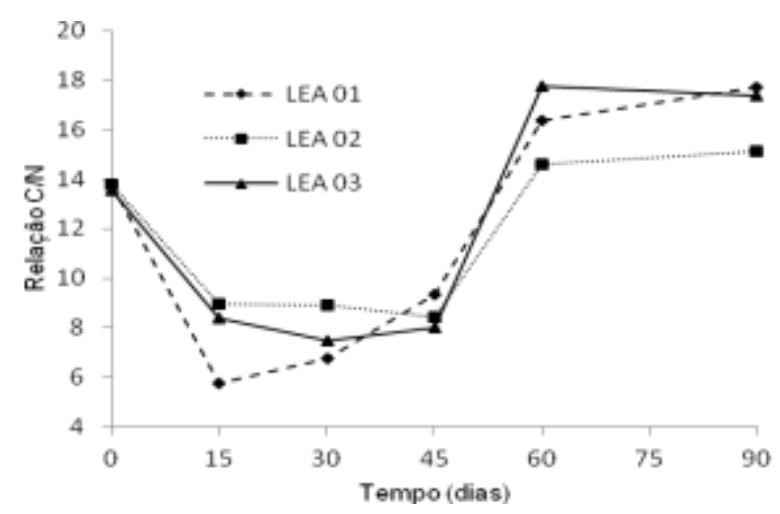

(b)

FIGURA 4. Variação da relação C/N em função do tempo de compostagem: (a) composteira; (b) LEA 01, LEA 02, LEA 03. Variation of $\mathbf{C} / \mathbf{N}$ ratio versus time of composting. (a) Bin compost, (b) ASP 01, ASP 02, ASP 03.

A relação $\mathrm{C} / \mathrm{N}$ da composteira (Figura 4a) e das LEAs (Figura 4b) apresentou decréscimo nas primeiras análises, porém, ao final do período de compostagem, ficou superior à inicial. Os valores iniciais e finais da relação $\mathrm{C} / \mathrm{N}$ encontrados no material submetido aos diferentes tratamentos foram: composteira (19,2 e 22,7); LEA 01 (13,8 e 18,7); LEA $02(13,8$ e 14,6) e LEA 03 (13,6 e 17,4). As variações iniciais encontradas estão relacionadas ao período de montagem dos experimentos. A composteira foi montada por volta do $20^{\circ}$ dia do ciclo de engorda dos frangos, quando a mortalidade ainda era baixa, sendo que as leiras foram montadas por volta do $40^{\circ}$ dia, quando a mortalidade é mais elevada. Assim, com maior disponibilidade de carcaças, a relação C/N ficou menor. Acredita-se que as variações encontradas no final do processo estejam relacionadas às diferentes degradabilidades dos materiais envolvidos, diferentes taxas de aeração e à heterogeneidade das misturas. Sendo que estas últimas favorecem o aparecimento de regiões na 
massa em compostagem, cujas variações das variáveis $\mathrm{pH}$, temperatura, relação $\mathrm{C} / \mathrm{N}$ sejam diferentes e, portanto, a taxa de volatilização do nitrogênio, na forma de amônia, também. KIM et al. (2010), estudando a influência da taxa de aeração na dinâmica do nitrogênio na compostagem, observaram que altas taxas de aeração foram responsáveis por cerca de $85 \%$ da remoção de nitrogênio na forma de $\mathrm{NH}_{3}$. Tal como observado por esses autores, as LEAs apresentaram maior perda de nitrogênio que a Composteira; entretanto, a relação $\mathrm{C} / \mathrm{N}$ final nos primeiros ficou bem inferior à obtida no material processado na composteira. Acredita-se que isso se deva, também, à maior eficiência das LEAs na estabilização da matéria orgânica, denotada pela redução de SV. KUMAR et al. (2007), trabalhando com composteira, também observaram aumento no valor da relação $\mathrm{C} / \mathrm{N}$ no composto final, em comparação com o obtido inicialmente. Esses autores obtiveram valores finais de relação $\mathrm{C} / \mathrm{N}$ de $15,9( \pm 0,76)$ a $23,19( \pm 4,62)$, no tratamento com palha de arroz, e de $16,35( \pm 1,06)$ a $18,0( \pm 1,64)$, no tratamento com feno de sorgo. FLYNN \& WOOD (1996), analisando as mudanças químicas e de temperaturas na compostagem de cama de frango, também observaram, em leiras que iniciaram com relação $\mathrm{C} / \mathrm{N}$ de 24; 26 e 26:1, após 84 dias de compostagem, relações $\mathrm{C} / \mathrm{N}$ aumentadas ou ligeiramente reduzidas para valores de 22; 27 e 28:1, respectivamente. Como pode ser observado, para os diferentes trabalhos citados, o aumento da relação $\mathrm{C} / \mathrm{N}$ entre o início e o fim do processo de compostagem é comum em misturas cujas relações $\mathrm{C} / \mathrm{N}$ se encontram bem abaixo de 30:1, considerado ideal.

Na Figura 5, estão apresentados os gráficos de variação da concentração de sólidos voláteis (SV) em função do tempo de compostagem.

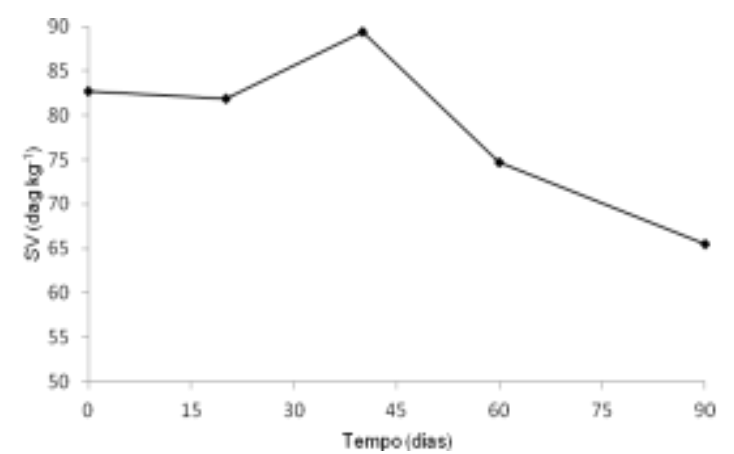

(a)

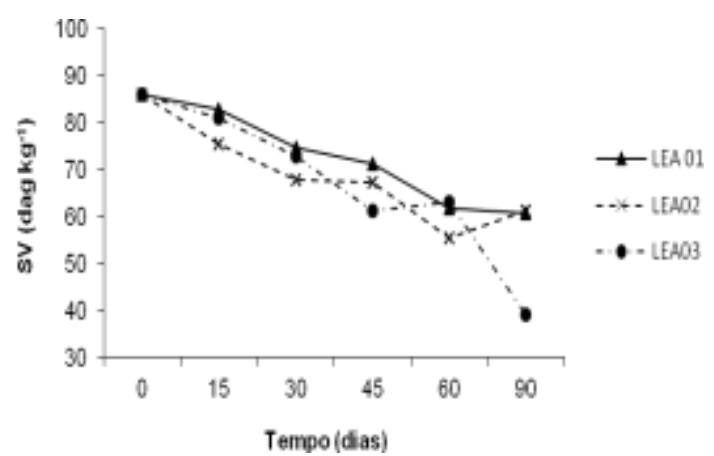

(b)

FIGURA 5. Variação na concentração de SV em função do tempo de compostagem: (a) composteira; (b) LEA 01, LEA 02, LEA 03. Variation in the concentration of VS versus time of composting. (a) Bin compost, (b) ASP 01, ASP 02, ASP 03.

Conforme pode ser observado na Figura 5, todos os tratamentos proporcionaram considerável redução na concentração de SV, sendo esta redução consequência da mineralização ou estabilização do material em compostagem.

Na Tabela 1, estão apresentados os valores médios percentuais de redução do conteúdo de SV em função dos diferentes tratamentos e dos dias decorridos após início dos experimentos.

TABELA 1. Valores percentuais médios de redução de Sólidos Voláteis (SV) em função dos tratamentos e dos dias decorridos após o início das operações. Average percentual values of VS reduction in fuction of the treatment and the days after the beginning of the operations.

\begin{tabular}{ccccc}
\hline \multirow{2}{*}{ Dias } & \multicolumn{4}{c}{ Tratamentos* } \\
\cline { 2 - 5 } & Composteira (\%) & LEA01 (\%) & LEA02 (\%) & LEA03 (\%) \\
\hline 60 & $9,66 \mathrm{Cb}$ & $23,96 \mathrm{Ba}$ & $35,37 \mathrm{Aa}$ & $26,61 \mathrm{Bb}$ \\
90 & $20,87 \mathrm{Ba}$ & $25,31 \mathrm{Ba}$ & $28,86 \mathrm{Bb}$ & $54,48 \mathrm{Aa}$ \\
\hline
\end{tabular}

*Letras maiúsculas iguais na mesma linha e letras minúsculas na mesma coluna não diferem entre si, pelo teste de Tukey, ao nível de $5 \%$ de probabilidade. 
A redução de SV da LEA $02(35,37 \%)$ (Tabela 1), nos primeiros 60 dias, foi superior aos demais tratamentos; porém, aos 90 dias, o resultado foi de $28,86 \%$, apresentando uma distorção. Essa distorção de valores pode ter ocorrido em função de a mineralização do material da leira ocorrer de maneira heterogênea, embora se tenha tido o cuidado de minimizar esse problema por meio de coleta em diferentes pontos e diferentes profundidades das leiras. Ao final dos 90 dias de compostagem, a LEA 03 (leira aerada com carcaças de frango trituradas, palha de café e cama de frango) obteve a maior redução de sólidos voláteis $(54,48 \%)$, sendo essa diferença significativa, a $5 \%$ de probabilidade, pelo teste de médias de Tukey. Dentre os fatores que podem ter contribuído para isso, estão a maior degradabilidade da palha de café quando comparada ao bagaço de cana-deaçúcar e à trituração das carcaças que acelera a degradação microbiana por aumentar a superfície específica do material.

$\mathrm{Na}$ Tabela 2, estão apresentados os resultados das análises microbiológicas de Salmonella e coliformes termotolerantes, efetuadas no material durante o período de sua compostagem.

De acordo com os resultados apresentados na Tabela 2 e com base no que está estabelecido na Resolução CONAMA 375/2006, que exige a ausência de Salmonella em amostra de $10 \mathrm{~g}$ de ST e contagem de organismos coliformes termotolerantes menor que $10^{3} \mathrm{NMP} \mathrm{g}^{-1}$ de ST, em lodo de esgoto a ser utilizado com fins agrícolas, pode ser observado que todos os tratamentos proporcionaram resultados satisfatórios, já nas primeiras análises, aos 15 dias (LEAs) e 20 dias (composteira), em relação ao aspecto sanitário.

TABELA 2. Variáveis microbiológicas avaliadas nos materiais durante o período de compostagem. Microbial variables assessed in the material during the composting.

\begin{tabular}{cccccc}
\hline Microrganismos & Dias & Composteira & LEA 01 & LEA 02 & LEA 03 \\
\hline \multirow{3}{*}{ Coliformes termotolerantes a } & 0 & $2,9 \times 10^{4}$ & $4,6 \times 10^{6}$ & $2,4 \times 10^{6}$ & $1,5 \times 10^{6}$ \\
$45^{\circ} \mathrm{C}$ & 15 & Não analisado & $<3$ & 9,2 & 3,6 \\
$(\mathrm{NMP} / \mathrm{g})$ & 20 & $<3$ & Não analisado & Não analisado Não analisado \\
& 30 & Não analisado & 3,6 & $<3$ & $<3$ \\
& 60 & $<3$ & Não analisado Não analisado Não analisado \\
\hline \multirow{3}{*}{ Salmonella } & 0 & Presença & Ausência & Presença & Ausência \\
& 15 & Não analisado & Ausência & Ausência & Ausência \\
& 20 & Ausência & Não analisado Não analisado Não analisado \\
& 30 & Não analisado & Ausência & Ausência & Ausência \\
& 60 & Ausência & Não analisado Não analisado Não analisado \\
\hline
\end{tabular}

Entretanto, análises sucessivas deveriam ser feitas para a confirmação dos resultados, já que, devido à heterogeneidade da massa de material em compostagem, pode ocorrer sua recontaminação. COSTA et al. (2006), em experimento semelhante, porém adicionando $1 \mathrm{~L}$ de substrato contendo Salmonella $s p$ na diluição de $10^{8}$ unidades por $\mathrm{mL}$, na última camada da leira de compostagem mantida em composteira (área aproximada de $4 \mathrm{~m}^{2}$ ), não conseguiram eliminação satisfatória desses microrganismos, na primeira fase do processo. Sendo, então, sugerida a execução de uma segunda fase de compostagem quando ela for conduzida em composteiras. ORRICO et al. (2007) e ORRICO JÚNIOR et al. (2010) conseguiram a eliminação total de microrganismos termotolerantes na compostagem em leiras, por reviramento, de dejetos de cabra e carcaças de aves (segunda fase), respectivamente.

\section{CONCLUSÕES}

- os materiais palha de café e bagaço de cana-de-açúcar proporcionaram compostabilidade satisfatória, quando associados à cama de frango e carcaças de frango. 
- na composteira, principalmente na primeira fase, o conteúdo de água e oxigênio no material foi fator limitante à degradação, o que se verificou pela baixa redução na concentração de sólidos voláteis.

- as LEAs mostraram-se mais eficientes na estabilizaçao da matéria orgânica que a Composteira, denotada pela maior redução de SV.

- nas LEAs, a palha de café proporcionou melhores resultados que o bagaço de cana-deaçúcar na compostagem da carcaça de frango, com maior redução de SV.

- a trituração das carcaças de frango, utilizada nos tratamentos LEA 02 e 03, proporcionou maior redução de $\mathrm{SV}$.

- todos os tratamentos apresentaram reduções das concentrações de $\mathrm{N}$ devido ao excesso desse nutriente nos processos.

- todos os sistemas avaliados mostraram-se eficientes na eliminação ou na redução dos microrganismos Salmonella e coliformes termotolerantes, a níveis compatíveis com o que é exigido pela legislação CONAMA 375.

\section{REFERÊNCIAS}

ABREU, P. G.; PEDROSO-DE-PAIVA, D.; ABREU, V. M. N.; COLDEBELLA, A.; CESTONARO, T. Casca de arroz e palhada de soja na compostagem de carcaças de frangos de corte. Acta Scientiarum, Maringá, v.33, n.1, p. 51-57, 2011.

AMERICAN PUBLIC HEALTH ASSOCIATION. Standard methods for the examination of water and wastewater. $20^{\text {th }}$ ed. New York: APHA, WWA. WPCR, 1998.

BRASIL. Ministério do Meio Ambiente. Resolução CONAMA n. 375, de 29 de agosto de 2006. Define critérios e procedimentos para o uso agrícola de lodos de esgotos gerados em estações de tratamento de esgoto sanitário e seus produtos derivados, e dá outras providências. Brasília, 2006.

COSTA, M.S.S.M.; COSTA, L.A.M.; PELÁ, C.J.S.; DECARLI, L.D.; MATTER, U.F.

Desempenho de quatro sistemas para compostagem de carcaça de aves. Revista Brasileira de Engenharia Agrícola e Ambiental, Campina Grande, v.10, n.3, p.692-698, 2006.

DAM, A.; NIBBELINK, B. G.; WARD, D. Windrow composting of poultry carcasses. Order n. 09017, AGDEX 720/450, April 2009. Disponível em:

http://www.omafra.gov.on.ca/english/engineer/. Acesso em: 1 fev. 2011.

DEFILIPO, B.V.; RIBEIRO, A.C. Análise química do solo (Metodologia). 2.ed. Viçosa: UFV, 1997. 26 p. (Boletim de Extensão)

FLYNN, R.P.; WOOD, C.W. Temperature and chemical changes during composting of broiler litter. Compost Science \& Utilization, Emmaus, v.4, n.3, p.62-70, 1996.

KIEHL, E.J. Fertilizantes orgânicos. São Paulo: Agronômica Ceres, 1985. 492 p.

KIM, J.; SONG, I.; JONG, J.; LEE, S.; KIM, P.; JEONG, E.; PARK, J.; CHOUNG, Y. Influence of aeration rate on nitrogen during blackwater composting. Desalination, Amsterdam, n.251, p.298$307,2010$.

KUMAR, V.R.S.; SIVAKUMAR, K.; PURUSHOTHAMAN, M.R.; NATARAJAN, A.; AMANULLAH, M.M. Chemical changes during composting of dead birds with caged layer manure. Journal of Applied Sciences Research, v.3, n.10, p.1.100-1.104, 2007.

MIZUSAKI, M. Y. Reestruturação produtiva na avicultura em Mato Grosso do Sul. Geosul, Florianópolis, v.22, n.44, p.135-154, 2007.

MOREIRA, D.A.; MATOS, A.T.; SARTORI, SILVA, N.C.L.; M.A., BARROS, R.T.P.; LUIZ, F.A.R. Perda de carga no fluxo de ar forçado em colunas de material orgânico com diferentes 
profundidades e estádios de degradação bioquímica. Engenharia na Agricultura, Viçosa-MG, p.238-247, 2008.

ORRICO, A.C.A.; LUCAS JÚNIOR, J.; ORRICO JÚNIOR, M.A.P. Alterações físicas e microbiológicas durante a compostagem dos dejetos de cabras. Engenharia Agrícola, Jaboticabal, v.27, n.3, p.764-772, set./dez. 2007.

ORRICO JÚNIOR, M.A.P.; ORRICO, A.C.A.; LUCAS JÚNIOR, J. Compostagem dos resíduos da produção agrícola: cama de frangos e carcaças de aves. Engenharia Agrícola, Jaboticabal, v.30, n.3, p.538-545, 2010.

PEREIRA NETO, J. T. Manual de compostagem, processo de baixo custo. Viçosa-MG: Ed. UFV, 2007. $81 \mathrm{p}$.

PUYUELO, B.; GEA, T.; SÁNCHEZ, A. A new control strategy for the composting process based on the oxygen uptake rate. Chemical Engineering Journal, Lausanne, n.165, p.161-169, 2010.

SILVA, N.C.L.; MATOS, A.T.; SARTORI, M.A.; MOREIRA, D.A.; BARROS, R.T.P.; LUIZ, F.A.R. Variação na pressão estática de ar insuflado em diferentes vazões específicas em colunas de material orgânico com diferentes estádios de degradação bioquímica. Acta Scientiarium Agronomy, Maringá, v.30, n.2, p.165-170, 2008.

STENTIFORD, E.I.; PEREIRA NETO; MARA, D. D. Diversity of composting system. In: MARA, D.D. (ed.). Low cost composting - Research Monographs in Tropical Public Health Engineering. Leeds: University of Leeds, 1996.

UBA. UNIÃO BRASILEIRA DE AVICULTURA. Relatório Anual de 2009. Brasília, 2010.

WANG, K.; LI, W.; GUO, J.; ZOU, J.; LI, Y.; ZHANG, L. Spatial distribution of dynamics characteristic in the intermittent aeration static composting of sewage sludge. Bioresource Technology, Essex, n.102, p.5.528-5.532, 2011. 